\author{
Marquette University \\ e-Publications@Marquette
}

Biomedical Engineering Faculty Research and

Publications

Biomedical Engineering, Department of

8-2007

\title{
Soleus H-reflex Excitability Changes in Response to Sinusoidal Hip Stretches in the Injured Human Spinal Cord
}

\author{
Maria Knikou \\ Northwestern University \\ Brian D. Schmit \\ Marquette University, brian.schmit@marquette.edu \\ Debjani Chaudhuri \\ Marquette University \\ Elizabeth Kay \\ Rehabilitation Institute of Chicago \\ WIlliam Zev Rymer \\ Northwestern University
}

Follow this and additional works at: https://epublications.marquette.edu/bioengin_fac

Part of the Biomedical Engineering and Bioengineering Commons

\section{Recommended Citation}

Knikou, Maria; Schmit, Brian D.; Chaudhuri, Debjani; Kay, Elizabeth; and Rymer, WIlliam Zev, "Soleus Hreflex Excitability Changes in Response to Sinusoidal Hip Stretches in the Injured Human Spinal Cord" (2007). Biomedical Engineering Faculty Research and Publications. 313.

https://epublications.marquette.edu/bioengin_fac/313 


\title{
Soleus H-reflex Excitability Changes in Response to Sinusoidal Hip Stretches in the Injured Human Spinal Cord
}

\author{
Maria Knikou \\ Sensory Motor Performance Program, Rehabilitation Institute of \\ Chicago \\ Chicago, IL \\ Dept. of Physical Medicine and Rehabilitation, Northwestern \\ University Medical School \\ Chicago, IL \\ Dept. of Physical Therapy and Neuroscience, the Graduate \\ Center, City University of New York \\ Staten Island, NY

\section{Brian D. Schmit} \\ Sensory Motor Performance Program, Rehabilitation Institute of \\ Chicago \\ Chicago, IL \\ Dept. of Physical Medicine and Rehabilitation, Northwestern \\ University Medical School \\ Chicago, IL \\ Dept. of Biomedical Engineering, Marquette University \\ Milwaukee, WI
}




\title{
Debjani Chaudhuri \\ Dept. of Biomedical Engineering, Marquette University \\ Milwaukee, WI
}

\author{
Elizabeth Kay \\ Sensory Motor Performance Program, Rehabilitation Institute of \\ Chicago \\ Chicago, IL \\ William Zev Rymer \\ Sensory Motor Performance Program, Rehabilitation Institute of \\ Chicago \\ Chicago, IL \\ Dept. of Physical Medicine and Rehabilitation, Northwestern \\ University Medical School \\ Chicago, IL
}

\begin{abstract}
:
Imposed static hip stretches substantially modulate the soleus $\mathrm{H}$-reflex in people with an intact or injured spinal cord while stretch of the hip flexors affect the walking pattern in lower vertebrates and humans. The aim of this study was to assess the effects of dynamic hip stretches on the soleus $\mathrm{H}$ reflex in supine spinal cord injured (SCI) subjects. Sinusoidal movements were imposed on the right hip joint at $0.2 \mathrm{~Hz}$ by a Biodex system. H-reflexes from the soleus muscle were recorded as the leg moved in flexion or extension. Stimuli were sent only once in every hip movement cycle that each lasted $5 \mathrm{~s}$. Torque responses were recorded at the hip, knee, and ankle joints. A hip phase-dependent soleus $\mathrm{H}$-reflex modulation was present in all subjects. The reflex was facilitated during hip extension and suppressed during hip flexion. There were no significant differences in pre- or post-stimulus soleus background activity between the two conditions. Oscillatory responses were present as the hip was maximally flexed. Sinusoidal hip stretches modulated the soleus $\mathrm{H}$-reflex in a manner similar to that previously observed following static hip stretches. The amount of reflex facilitation depended on the angle of hip extension. Further research is needed on the afferent control of spinal reflex pathways in health and disease in order to better understand the neural
\end{abstract}

Neuroscience Letters, Vol. 423, No. 1 (August 2015): pg. 18-23. DOI. This article is $\subset$ Elsevier and permission has been granted for this version to appear in e-Publications@Marquette. Elsevier does not grant permission for this article to be further copied/distributed or hosted elsewhere without the express permission from Elsevier. 
NOT THE PUBLISHED VERSION; this is the author's final, peer-reviewed manuscript. The published version may be accessed by following the link in the citation at the bottom of the page.

control of movement in humans. This will aid in the development of rehabilitation strategies to restore motor function in these patients.

Keywords: afferents, movement, oscillatory activity, sensorimotor integration. 
NOT THE PUBLISHED VERSION; this is the author's final, peer-reviewed manuscript. The published version may be accessed by following the link in the citation at the bottom of the page.

\section{Introduction}

The electrically induced Hoffmann or H-reflex resembles the short latency component of the monosynaptic stretch reflex evoked during dynamic conditions, which bypasses the fusimotor drive that affects the spindle's afferent sensitivity [24]. Thus, one can assess the modulation of synaptic efficacy of large Ia afferent fibers onto amotoneurones and establish a spinally mediated reflex modulation. Depending on the arrangement of a conditioning stimulus, sensorimotor integration from the periphery or from supraspinal centers can be assessed in health and disease [16]. Numerous studies have examined the $\mathrm{H}$-reflex modulation pattern and the mechanisms involved during various tasks (task dependence) or during different phases of a task (phase dependence) $[2,4]$ to provide evidence about the neural control of movement and posture in humans.

The soleus $\mathrm{H}$-reflex is modulated during human locomotion in a phase-dependent manner, so it is depressed at early stance and during the swing phase, while it is facilitated at late stance $[3,6]$. However, soleus $\mathrm{H}$-reflex facilitation has also been reported during the transition from swing to stance [30]. Following a spinal cord injury (SCI), the soleus $\mathrm{H}$-reflex modulation pattern varies from a relatively normal pattern to complete absence of phasic modulation [31]. Possible mechanisms that could account for the reflex modulation during walking are spinal locomotor circuits, proprioceptive feedback related to leg movement [2], and descending drive that adjusts the $\mathrm{H}$ reflex threshold [11]. Interestingly, the knee joint does not contribute to reflex modulation since blocking this joint does not alter the soleus $\mathrm{H}$-reflex modulation pattern in humans during walking [29].

Previous studies have shown that static changes of the ankle or hip joints powerfully modulate Ia afferent transmission to amotoneurones $[19,20,28]$. We have previously reported that static stretches at the hip modulate the soleus $\mathrm{H}$-reflex similarly in spinalintact and spinal-injured subjects. Specifically, the soleus $\mathrm{H}$-reflex is depressed when the ipsilateral hip is statically positioned between $30^{\circ}$ to $75^{\circ}$ of flexion, and is facilitated with the hip hyper-extended to $10^{\circ}$ $[19,20]$. The purpose of this study was to assess the soleus H-reflex modulation pattern in response to sinusoidal stretches at the hip joint

Neuroscience Letters, Vol. 423, No. 1 (August 2015): pg. 18-23. DOI. This article is (C) Elsevier and permission has been granted for this version to appear in e-Publications@Marquette. Elsevier does not grant permission for this article to be further copied/distributed or hosted elsewhere without the express permission from Elsevier. 
in people with clinically incomplete SCI. We hypothesized that dynamic sinusoidal hip movements would induce a similar reflex modulation pattern to that previously observed during static hip stretches but of larger amplitude. Part of this work has been reported in abstract form $[5]$.

Experiments were conducted after ethics committee approval (Northwestern University, Chicago IL, USA) in accordance with the 1964 Declaration of Helsinki. Written informed consent was obtained from all volunteers before participation. Seven subjects with lesions ranging from cervical $(C) 5$ to thoracic $(T) 11$ spinal segments and clinically incomplete SCI (ASIA grade C) participated in this study. The same subjects participated in previous studies and their detailed characteristics are described elsewhere [21].

The H-reflex was elicited by stimulating the right posterior tibial nerve in the popliteal fossa using a monopolar electrode with a 1-ms pulse generated by a constant current stimulator (DS7A; Digitimer Ltd., UK), and was recorded from the right soleus muscle using a differential bipolar electrode (DE-2.1; DelSys, MA, USA). The indifferent electrode was placed just above the patella for selective stimulation of the nerve trunk. At the beginning of each experiment, a hand-held monopolar electrode with stainless-steel head was used as a probe to establish the optimal site for stimulating the tibial nerve, and was defined as the site where Ia afferents could selectively be excited at low intensities. The probe was then replaced by a permanent electrode (N-10-A, Ambu Inc., Denmark) under constant pressure, and the evoked responses were observed on a digital oscilloscope (Tektronics Inc., Beaverton, OR). Next, the maximal M-wave (elicited every $5 \mathrm{~s}$ ) was measured online as the peak-to-peak amplitude of the un-rectified waveform using the oscilloscope, and was saved for further analysis. Since the sensitivity of the H-reflex to facilitation or inhibition depends on the size of the test reflex [8], we adjusted the stimulus strength to evoke control reflexes (subjects supine) that ranged from 15 to $35 \%$ of the maximal M-wave across subjects (see Fig. 1A), and verified that each reflex was elicited on the ascending part of the recruitment cure.

Neuroscience Letters, Vol. 423, No. 1 (August 2015): pg. 18-23. DOI. This article is (C) Elsevier and permission has been granted for this version to appear in e-Publications@Marquette. Elsevier does not grant permission for this article to be further copied/distributed or hosted elsewhere without the express permission from Elsevier. 
NOT THE PUBLISHED VERSION; this is the author's final, peer-reviewed manuscript. The published version may be accessed by following the link in the citation at the bottom of the page.

A

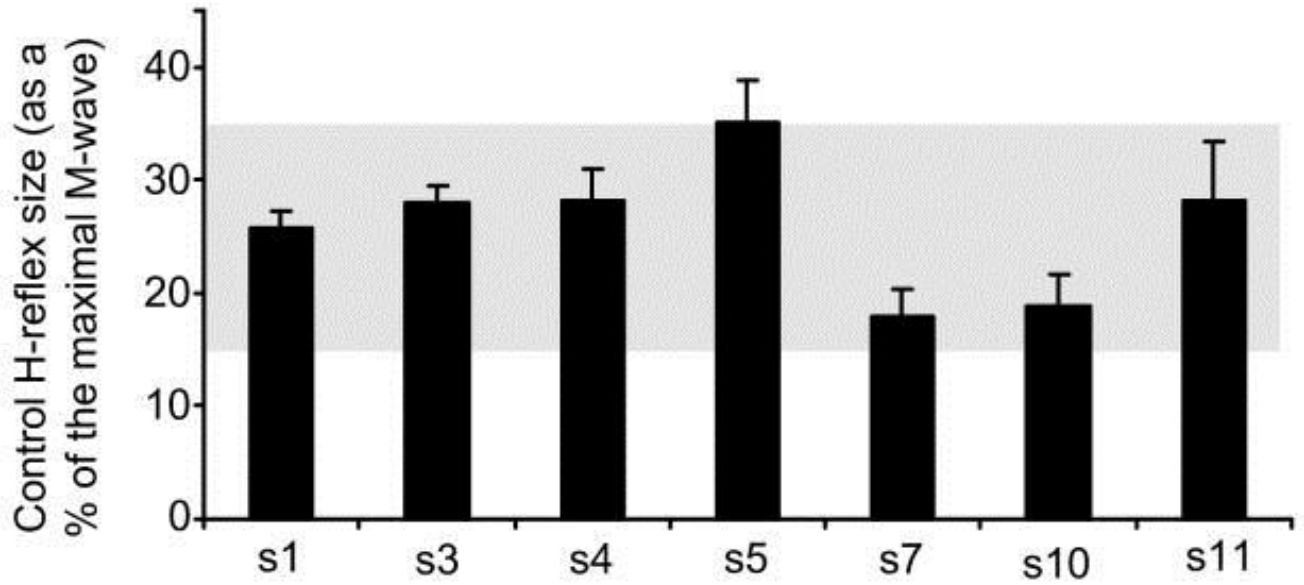

$\mathrm{B}$

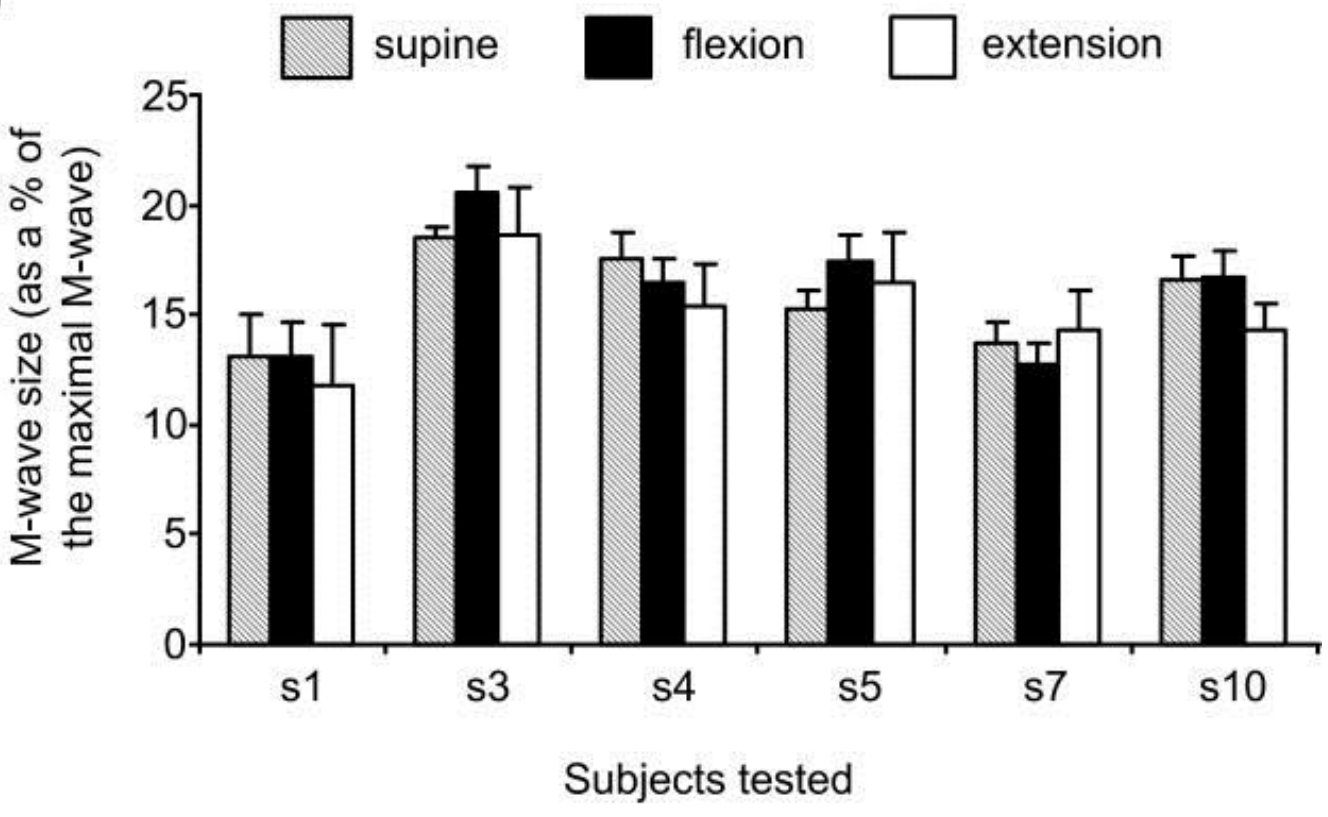

Fig. 1 Characteristics of $M$-wave and H-reflex under control conditions and during sinusoidal hip stretches.

For each subject identified on the abscissa, the average control H-reflex (A) and the $\mathrm{M}$ wave recorded during control conditions and following imposed sinusoidal hip stretches (B) are illustrated as a percentage of the maximal M-wave. Control H-reflexes varied from 18 to $35 \%$ of the maximal M-wave across subjects. The M-waves were not statistically significant different across experimental conditions $(P>0.05)$. In subject 11 , the M-wave was not present at these stimulus intensities. 
The soleus $\mathrm{H}$-reflexes during imposed sinusoidal hip stretches were elicited once every movement cycle and were recorded with subjects supine. The stimulus to the tibial nerve was delivered either at mid-flexion or mid-extension depending on the test condition. In each subject, two control reflexes were randomly recorded with two different series of conditioned reflexes. Ten sweeps were recorded for each control and conditioned reflex. The M-wave amplitude was continually monitored to ensure stability in the stimulation and recording procedures. In Fig. $1 \mathrm{~B}$, the average $M$-wave size as a percentage of the maximal $\mathrm{M}$-wave is indicated for each subject under control conditions and during imposed sinusoidal hip stretches. No statistically significant differences were found on the M-wave amplitude across subjects and conditions $(P=0.74)$, verifying stable conditions during leg movement.

With subjects supine, the right leg was secured in a customized leg brace that incorporated single-axis torque transducers (Himmelstein Inc., Hoffman Estates, IL, USA) at the knee and ankle linkages. Passive sinusoidal movements at the hip were imposed at a frequency of $0.2 \mathrm{~Hz}$ by the Biodex system (System 3, Biodex Medical Systems Inc., Shirley, NY). At this frequency, each hip movement cycle lasted $5 \mathrm{~s}$. The total hip range of movement varied from $47^{\circ}$ to $52^{\circ}$ across subjects. The right ankle and knee joints were set at $20^{\circ}$ of plantar flexion and $30^{\circ}$ of flexion, respectively. All signals were band pass filtered $(20-250 \mathrm{~Hz})$ before being sampled at $2 \mathrm{kHz}$ using a data acquisition card and customized data acquisition programs (LabVIEW software, National Instruments, Austin, TX, USA).

The soleus $\mathrm{H}$-reflex and $\mathrm{M}$-wave of the control and conditioned reflexes were full-wave rectified, and their sizes were measured as the area under the corresponding waveforms. For each subject, the conditioned reflexes were expressed as a percentage of the mean size of the control reflex. A one-way analysis of variance (ANOVA) was applied to the experimental data sets to test for statistically significant differences between the control and conditioned reflexes at a $95 \%$ of confidence level. The average $\mathrm{H}$-reflex size from each subject was then grouped based on the direction of the hip movement (e.g. flexion/extension). An ANOVA for repeated measures along with post hoc Bonferroni tests were conducted to establish statistically significant differences between the conditioned reflexes across subjects and

Neuroscience Letters, Vol. 423, No. 1 (August 2015): pg. 18-23. DOI. This article is (C) Elsevier and permission has been granted for this version to appear in e-Publications@Marquette. Elsevier does not grant permission for this article to be further copied/distributed or hosted elsewhere without the express permission from Elsevier. 
direction of hip movement. The M-waves of the control and conditioned $\mathrm{H}$-reflexes were expressed as a percentage of the maximal $M$-wave (see Fig. 1B). A one-way ANOVA was used to test for differences between the $M$-waves of the reflexes recorded under control conditions and during hip movement.

For each subject, the soleus background activity was measured from the rectified EMG recordings at an interval of $50 \mathrm{~ms}$ and 70-100 $\mathrm{ms}$ before and after tibial nerve stimulation, respectively. For both cases the mean rectified EMG was computed for a period of $50 \mathrm{~ms}$. This calculation was conducted separately for reflexes elicited during hip flexion and extension. For each subject, a two-way ANOVA was applied to the data representing the pre- and post-stimulus soleus EMG activity during hip flexion and extension. The average of pre- and post-stimulus soleus EMG activity from each subject was then grouped based on the phase of the movement that the stimulus was delivered (flexion or extension) and two-way ANOVA for repeated measures was applied to the data.

For each subject, a movement trial without tibial nerve stimulation was recorded. The movement cycle during which the muscles were quiescent was used as a measure of the non-reflex torques associated with the combined effects of inertia, gravity, and the passive resistance of the limb and instrumented leg brace. The hip, knee, and ankle joint torques from this trial were subtracted from the respective joint torques measured when $\mathrm{H}$-reflexes were recorded.

This difference represented the reflexive torque responses initiated by hip movement and was low pass filtered at $2 \mathrm{~Hz}$. The average of these filtered data was used as an estimate of the torque response for each specific joint and subject. Results are presented as mean values along with the standard error of the mean (SEM).

A representative example of the effects of sinusoidal hip movement on the soleus H-reflex is shown in Fig. 2A. Relative to the control reflex (solid line), the soleus $\mathrm{H}$-reflex was significantly facilitated when the hip moved in extension (dashed line) and depressed during hip flexion (dotted line). In this subject (s11), although the control H-reflex was $27 \%$ of the maximal M-wave (see Fig. $1 \mathrm{~A}$ ) the $M$-wave was absent.

Neuroscience Letters, Vol. 423, No. 1 (August 2015): pg. 18-23. DOI. This article is (C) Elsevier and permission has been granted for this version to appear in e-Publications@Marquette. Elsevier does not grant permission for this article to be further copied/distributed or hosted elsewhere without the express permission from Elsevier. 

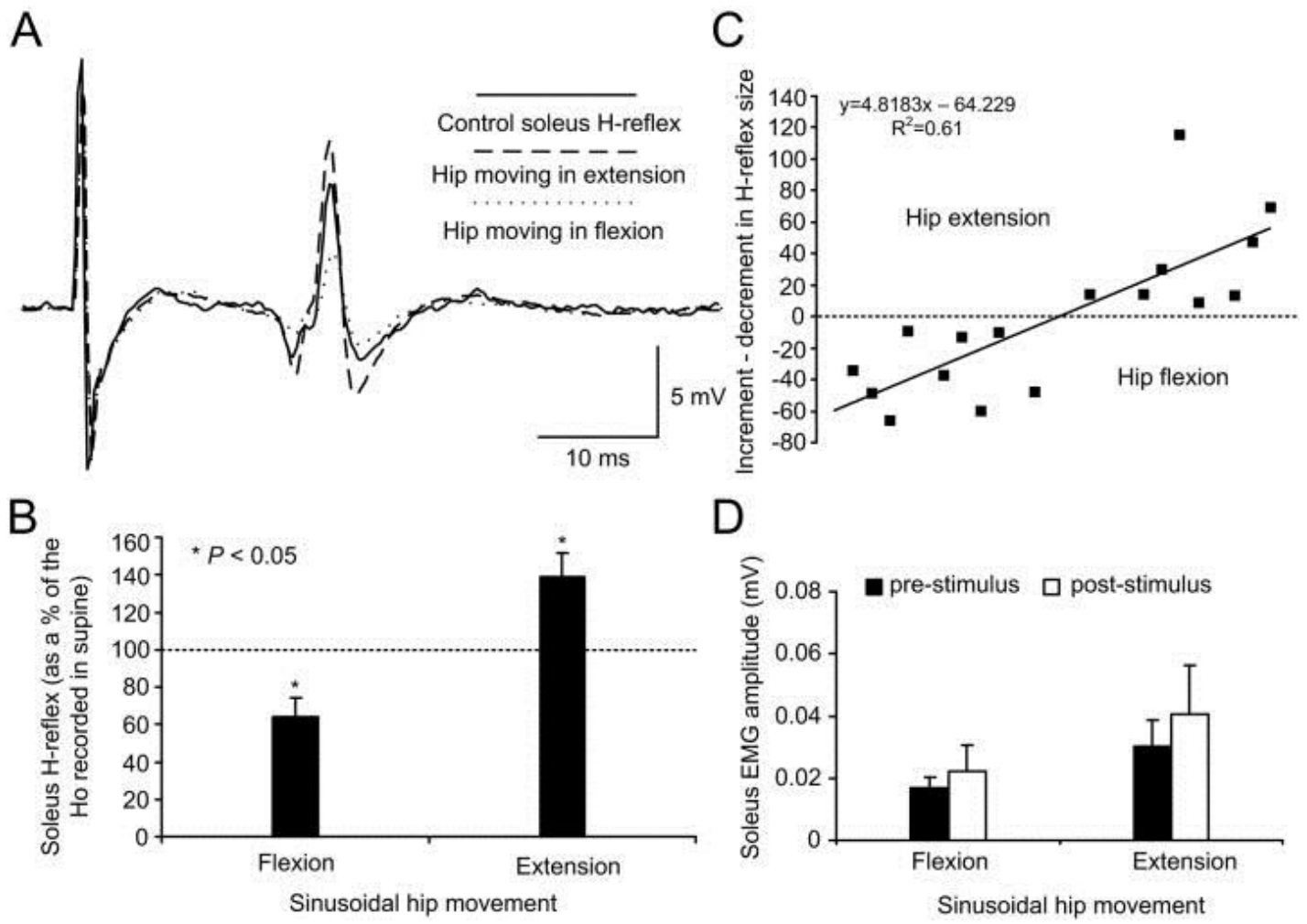

Fig. 2 Soleus H-reflex excitability changes in response to sinusoidal hip stretches.

(A) Waveform average of the soleus H-reflex ( $n=10$ sweeps) recorded in one subject (S11) during sinusoidal hip flexion (dotted line), extension (dashed line), and under control conditions (solid line). (B) Overall (all subjects tested) mean size of the soleus $\mathrm{H}$ reflex during hip flexion and extension as a percentage of the mean size of the control reflex. (C) The relationship between changes in $\mathrm{H}$-reflex amplitude and hip movement is indicated. Each point represents the difference in amplitude between the control and the conditioned reflex. The soleus $\mathrm{H}$-reflex modulation was strongly related to the hip angle during sinusoidal movements $\left(R^{2}=0.61\right)$. (D) The overall average amplitude of preand post-stimulus soleus background activity is illustrated for all cases where the soleus $\mathrm{H}$-reflex was elicited as the hip moved in flexion and extension. No significant differences were found between pre- and post-stimulus soleus EMG activity during hip flexion and extension $(P>0.05)$. In all graphs error bars represent the standard error of the mean.

The average of all of the H-reflexes recorded during sinusoidal hip movement in the sagittal plane is illustrated in Fig. 2B. The soleus $\mathrm{H}$-reflex was reduced to $64 \pm 10 \%$ of the control reflex values $(P<0.05)$ during hip flexion. Conversely, during hip extension the soleus $\mathrm{H}$-reflex was facilitated, reaching an overall amplitude of 
$139 \pm 13 \%$ of the control reflex $(P<0.05)$. The relationship between changes in $\mathrm{H}$-reflex amplitude and hip movement is illustrated in Fig. 2C. The changes in $\mathrm{H}$-reflex amplitude present the difference between the amplitude of the conditioned and control reflexes and are indicated as single points. These points represent data from all SCI subjects, and suggest that the nature of reflex modulation (e.g. facilitation or inhibition $)$ is linearly related to the hip angle $(y=4.8183 x-64.229$, $\left.R^{2}=0.61\right)$. The hip-phase dependent soleus $\mathrm{H}$-reflex modulation occurred without significant changes of the soleus background EMG activity. A two-way ANOVA (all subjects tested) showed that the preand post-stimulus soleus EMG activity were not statistically significant different during hip flexion and extension $(P=0.059)$ and for pre/post stimulus timing ( $P=0.298)$ (Fig. 2D).

Imposed sinusoidal hip movement produced joint forces in a phase-dependent manner. Extensor torque responses at the hip were present when this joint passed peak flexion and coincided with diametrically opposite torques at the knee (Fig. 3). In contrast, hip flexor torque responses were mostly present when the hip passed midflexion. The hip and knee joint torques were generally oscillatory at peak hip flexion. In summary, the hip and knee joints showed a stereotyped pattern of torque expression, regardless of the stimulus timing with respect to the hip movement. However, the ankle torques depended on the timing of the stimulus to the tibial nerve relative to the phase of the hip movement. 


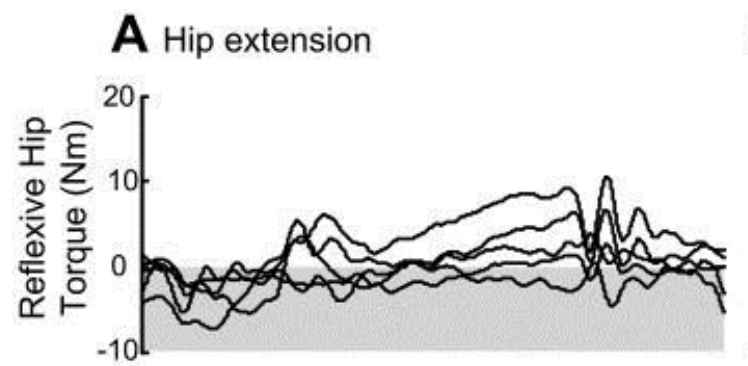

B Hip flexion
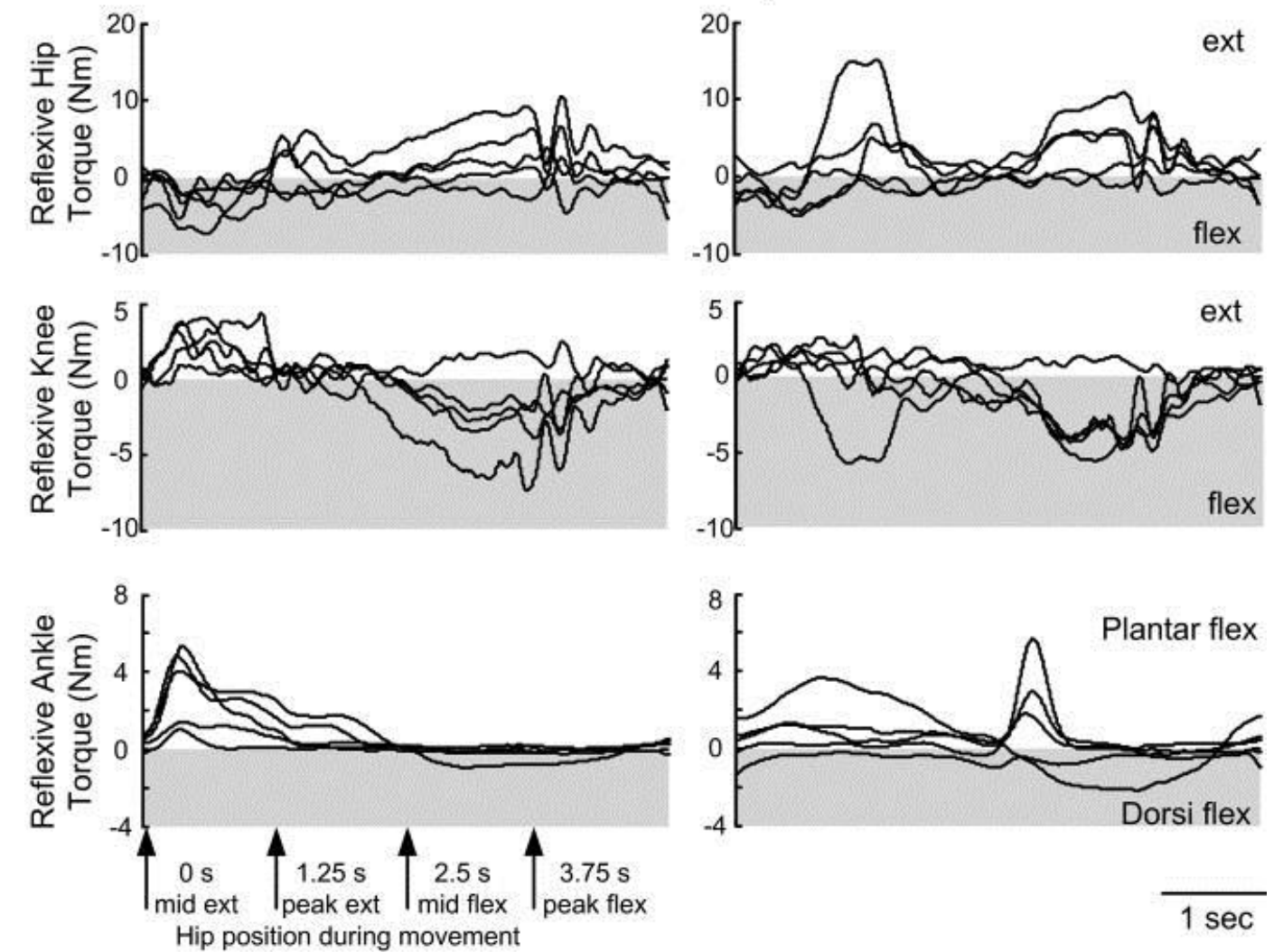

Fig. 3 Reflexive joint torques in response to sinusoidal hip stretches.

Torques $(\mathrm{Nm})$ above zero designate extension and those below zero designate flexion.

The position of the hip during movement is indicated by the vertical arrows (mid extension at $0 \mathrm{~s}$, peak extension at $1.25 \mathrm{~s}$, mid flexion at $2.5 \mathrm{~s}$ and peak flexion at $3.75 \mathrm{~s}$ ). For extension trials (A) stimuli were delivered at $0 \mathrm{~s}$ and for flexion trials (B) at $2.5 \mathrm{~s}$. Oscillatory joint torque responses were observed when the hip reached peak flexion.

The main finding of this study was that in the partially disrupted human spinal cord, imposed sinusoidal stretches induced a hip-phase dependent modulation of the soleus $\mathrm{H}$-reflex that occurred with stable ongoing background activity of the involved muscle. This observation is consistent with modulation of reflex pathways by muscle afferents that have been implicated in the reflex regulation of movement and locomotion.

The size of the M-wave was stable across subjects and experimental conditions (Fig. 1B), suggesting a constant afferent volley. Further, the ongoing soleus background activity was not 
significantly different during hip flexion and extension (Fig. 2D). Thus, it is unlikely that the observed hip-phase dependent reflex modulation was driven by a net increase or decrease in soleus a-motoneuronal excitability. However, we should note that the soleus background activity, although non significant, was larger during hip extension than during hip flexion. The soleus EMG expression may be related to an enhanced excitability of motoneurones during sinusoidal hip extension, and probably be influenced by the oscillatory responses (Fig. 3) of the hip and knee joints.

It is well established that muscle spindles are sensitive to both rate of stretch and muscle static length. Small sinusoidal stretches in humans modulate the discharge rate of the primary muscle afferents in a linear fashion [17], contributing to the detection of passive movements. Thus, the observed reflex modulation was possibly mediated by the muscle spindles of the hip flexor and extensor muscles in response to the sinusoidal stretches. This is supported by the widely distributed pattern of heteronymous monosynaptic Ia excitation in the lower limb in humans $[25,26]$. Further, changes in the amount of presynaptic inhibition of Ia afferent terminals account for reflex modulation due to stretch [12], while static changes of the hip angle in supine spinal-intact subjects can abolish the conditioning reflex actions of the antagonist muscle afferents suggesting that hip muscle afferents modulate actions of presynaptic inhibitory interneurones [22]. Lastly, the central nervous system may had adjusted the excitability of spinal circuits in anticipation of movementrelated events and/or the posture of the limb as partly evident by modulation of presynaptic inhibition prior to execution of a movement [14], during which inputs of supraspinal origin are involved.

We hypothesized that sinusoidal hip stretches would lead to greater changes in the reflex amplitude compared to that previously observed during static hip muscle stretches [20]. The reflex facilitation during dynamic hip extension was of lower amplitude than the one observed with the hip statically extended (compare Fig. 2D with Fig. 2B in [20]). This can be attributed to the lack of hip hyper-extension in this study that occurred due to set up limitations (leg brace and Biodex chair), suggesting that the strength of reflex facilitation depends on the degree of hip hyper-extension. Further, 4 out of 7 subjects were taking Baclofen to manage spasticity. This drug affects selectively

Neuroscience Letters, Vol. 423, No. 1 (August 2015): pg. 18-23. DOI. This article is $\subset$ Elsevier and permission has been granted for this version to appear in e-Publications@Marquette. Elsevier does not grant permission for this article to be further copied/distributed or hosted elsewhere without the express permission from Elsevier. 
$\mathrm{GABA}_{B}$ receptors that are present on Ia afferent terminals and control the amount of calcium ion to the presynaptic afferent terminals [9]. If we assume that the effects were mediated at a presynaptic level then it is likely that the effects were masked by the medication in these subjects. In this context, the reduced soleus $\mathrm{H}$-reflex facilitation during dynamic hip stretches compared to that observed during static hip stretches may be related to homosynaptic post-activation depression due to the constant but varying range of muscle stretch imposed by the sinusoidal hip movements $[7,15]$. It should be noted that the efficiency of transmission across the synapses of Ia afferents in spastic patients is altered [27] due to mechanisms that remain largely unknown. Thus, given the indirect nature of our current experiments and the complex re-organization of the spinal cord circuits after an injury, a specific neuronal mechanism cannot be assigned.

An oscillatory activity of the hip and knee joints (Fig. 3) was observed with the hip maximally flexed just before extension, consistent with that previously observed in the same SCI subjects upon conditioning of the soleus $\mathrm{H}$-reflex with excitation of antagonist group I muscle afferents [21]. Clonic muscle activity is usually observed during the early stance where the hip is normally flexed at $30^{\circ}$ and shifts to $10^{\circ}$ of hip extension before foot flat [31]. Hipmediated sensory feedback is known to shape the walking pattern after SCI [10] and to account for phase-transitions and swing phase initiation in spinal cats during fictive locomotion $[1,13,23]$, suggesting that hip proprioceptors have a strong modulatory effect on locomotor reflex pathways. By analogy, this activity may be regarded as an expression of spinal locomotor pathways, which in absence of upright posture and limb loading may have been differentially expressed or augmented.

The present study provides evidence that the soleus $\mathrm{H}$-reflex is modulated linearly by sinusoidal hip stretches in a similar pattern to that reported for the soleus stretch reflex in standing SCI subjects [18]. It is suggested that hip-mediated sensory signals might contribute to the phase-dependent soleus $\mathrm{H}$-reflex modulation during human walking. However, we must caution that our study was conducted with subjects supine, so hip proprioceptors might interact differently with spinal reflex circuits during walking. Furthermore, the sinusoidal hip stretches were slower than the movements anticipated

Neuroscience Letters, Vol. 423, No. 1 (August 2015): pg. 18-23. DOI. This article is ( Elsevier and permission has been granted for this version to appear in e-Publications@Marquette. Elsevier does not grant permission for this article to be further copied/distributed or hosted elsewhere without the express permission from Elsevier. 
to occur during human walking. Thus, the current data should be interpreted cautiously with respect to studies performed in humans during walking, since the two conditions differ significantly. It is clear that further research regarding afferent control of spinal reflex pathways in health and disease is needed in order to better understand the neural basis of movement in humans and to develop rehabilitation strategies that optimize expression or 'appropriate' modulation of these spinal circuits.

\section{Acknowledgements}

This work was supported by the National Institute of Child Health and Human Development under the Grant No 5R03HD043951-2 to MK, and the National Institute of Neurological Disorders and Stroke, Grant No R01NS40901 to BDS.

\section{Footnotes}

Publisher's Disclaimer: This is a PDF file of an unedited manuscript that has been accepted for publication. As a service to our customers we are providing this early version of the manuscript. The manuscript will undergo copyediting, typesetting, and review of the resulting proof before it is published in its final citable form. Please note that during the production process errors may be discovered which could affect the content, and all legal disclaimers that apply to the journal pertain.

\section{References}

1. Andersson O, Grillner S. Peripheral control of the cat's step cycle: entrainment of the central pattern generators for locomotion by sinusoidal hip movements during fictive locomotion. Acta Physiol. Scand. 1983;118:229-239.

2. Brooke JD, Cheng J, Collins D, MacIlroy WE, Misiaszek WE, Staines WR. Sensori-sensory afferent conditioning with leg movement: gain control in spinal reflex and ascending paths. Progr. Neurobiol. 1997;51:393421.

3. Capaday C, Stein RB. Amplitude modulation of the soleus H-reflex in the human during walking and standing. J. Neurosci. 1986;6:1308-1313.

4. Capaday C. Neurophysiological methods for studies of the motor system in freely moving human subjects. J. Neurosci. Methods. 1997;74:201218.

Neuroscience Letters, Vol. 423, No. 1 (August 2015): pg. 18-23. DOI. This article is (C) Elsevier and permission has been granted for this version to appear in e-Publications@Marquette. Elsevier does not grant permission for this article to be further copied/distributed or hosted elsewhere without the express permission from Elsevier. 
NOT THE PUBLISHED VERSION; this is the author's final, peer-reviewed manuscript. The published version may be accessed by following the link in the citation at the bottom of the page.

5. Chaudhuri D, Knikou M, Schmit BD, Kay E. Modulation of soleus H-reflex and spinal inhibitory control systems during imposed sinusoidal hip movements in human spinal cord injury; XVI ISEK Congress; Torino, Italy. 2006

6. Crenna P, Frigo $\mathrm{C}$. Excitability of the soleus $\mathrm{H}$-reflex arc during walking and stepping in man. Exp. Brain Res. 1987;66:49-60.

Crone C, Nielsen J. Methodological implications of the post activation depression of the soleus H-reflex in man. Exp. Brain Res. 1989;78:2832.

7. Crone C, Hultborn H, Mazieres L, Nielsen J, Pierrot-Deseilligny E. Sensitivity of monosynaptic test reflexes to facilitation and inhibition as a function of the test reflex size: a study in man and the cat. Exp. Brain Res. $1990 ; 81: 35-45$.

8. Curtis DR, Cynther BD, Lacey G, Beattie DT. Baclofen: reduction of presynaptic calcium influx in the cat spinal cord in vivo. Exp. Brain Res. 1997;113:520-533.

9. Dietz V, Muller R, Colombo G. Locomotor activity in spinal man: significance of afferent input from joint and load receptors. Brain. 2002;125:2626-2634.

10. Ferris DP, Aagaard P, Simonsen EB, Farley CT, Dyhre-Poulsen P. Soleus $\mathrm{H}$-reflex gain in humans walking and running under simulated reduced gravity. J. Physiol. 2001;530:167-180.

11. Guissard N, Duchateau J, Hainaut K. Mechanisms of decreased motoneurone excitation during passive muscle stretching. Exp. Brain Res. $2001 ; 137: 163-169$

12. Hiebert GW, Whelan PJ, Prochazka A, Pearson KG. Contribution of hind limb flexor muscle afferents to the timing of phase transitions in the cat step cycle. J. Neurophysiol. 1996;75:1126-1137.

13. Hultborn $H$, Meunier S, Pierrot-Deseilligny $E$, Shindo M. Changes in presynaptic inhibition of Ia fibres at the onset of voluntary contraction in man. J. Physiol. 1987;389:757-772.

Neuroscience Letters, Vol. 423, No. 1 (August 2015): pg. 18-23. DOI. This article is (C) Elsevier and permission has been granted for this version to appear in e-Publications@Marquette. Elsevier does not grant permission for this article to be further copied/distributed or hosted elsewhere without the express permission from Elsevier. 
NOT THE PUBLISHED VERSION; this is the author's final, peer-reviewed manuscript. The published version may be accessed by following the link in the citation at the bottom of the page.

14. Hultborn $H$, Illert M, Nielsen J, Paul A, Ballegaard M M, Wiese H. On the mechanism of the post-activation depression of the $\mathrm{H}$-reflex in human subjects. Exp. Brain Res. 1996;108:450-462.

15. Hultborn $\mathrm{H}$. Changes in neuronal properties and spinal reflexes during development of spasticity following spinal cord lesions and stroke: studies in animal models and patients. J. Rehabil. Med. Suppl. 2003;41:46-55.

16. Kakuda N. Response of human muscle spindle afferents to sinusoidal stretching with a wide range of amplitudes. J. Physiol. 2000;527:397404.

17. Kawashima N, Yano H, Ohta Y, Nakazawa K. Stretch reflex modulation during imposed static and dynamic hip movements in standing subjects. Exp. Brain Res. 2006;174:342-350.

18. Knikou M, Rymer WZ. Effects of changes in hip joint angle on H-reflex excitability in humans. Exp. Brain Res. 2002;143:149-159.

19. Knikou M, Rymer WZ. Hip angle induced modulation of $\mathrm{H}$ reflex amplitude, latency and duration in spinal cord injured humans. Clin. Neurophysiol. 2002;113:1698-1708.

20. Knikou M, Chaudhuri D, Kay E, Schmit BD. Pre- and post-alpha motoneuronal control of the soleus $\mathrm{H}$-reflex during sinusoidal hip movements in human spinal cord injury. Brain Res. 2006;1103:123139.

21. Knikou M. Effects of changes in hip position on actions of spinal inhibitory interneurons in humans. Int. J. Neurosci. 2006;116:945-961.

22. Kriellaars DJ, Brownstone RM, Noga BR, Jordan LM. Mechanical entrainment of fictive locomotion in the decerebrate cat. J. Neurophysiol. 1994;71:2074-2086.

23. Loeb GE, Hoffer JA. Activity of spindle afferents from cat anterior thigh muscles. II. Effects of fusimotor blockade. J. Neurophysiol. $1985 ; 54: 565-577$.

24. Meunier S, Penicaud A, Pierrot-Deseilligny E, Rossi A. Monosynaptic Ia excitation and recurrent inhibition from quadriceps to ankle flexors and extensors in man. J. Physiol. 1990;423:661-675.

Neuroscience Letters, Vol. 423, No. 1 (August 2015): pg. 18-23. DOI. This article is (C) Elsevier and permission has been granted for this version to appear in e-Publications@Marquette. Elsevier does not grant permission for this article to be further copied/distributed or hosted elsewhere without the express permission from Elsevier. 
NOT THE PUBLISHED VERSION; this is the author's final, peer-reviewed manuscript. The published version may be accessed by following the link in the citation at the bottom of the page.

25. Meunier S, Pierrot-Deseilligny E, Simonetta M. Pattern of monosynaptic heteronymous Ia connections in the human lower limb. Exp. Brain Res. 1993;96:534-544.

26. Nielsen J, Petersen N, Crone C. Changes in transmission across synapses of Ia afferents in spastic patients. Brain. 1995;118:995-1004.

27. Robinson KL, McComas AJ, Belanger AY. Control of soleus motoneuron excitability during muscle stretch in man. J. Neurol. Neurosurg. Psychiatry. 1982;45:699-704.

28. Schneider C, Lavoie BA, Capaday C. On the origin of the soleus H-reflex modulation pattern during human walking and its task-dependent differences. J. Neurophysiol. 2000;83:2881-2890.

29. Simonsen EB, Dyhre-Poulsen $P$, Alkjaer $T$, Aagaard $P$, Magnusson SP. Inter-individual differences in $\mathrm{H}$ reflex modulation during normal walking. Exp. Brain Res. 2002;142:108-115.

30.Yang JF, Fung J, Edamura M, Blunt R, Stein RB, Barbeau H. H-reflex modulation during walking in spastic paretic subjects. Can. J. Neurosci. $1991 ; 18: 443-452$.

\title{
About the Authors
}

\author{
Maria Knikou : The Graduate Center, City University of New York, \\ 2800 Victory Blvd., Bldg. 5N-207, Staten Island NY \\ 10314 USA \\ Phone: (+1) 718.982.3316, Fax: (+1) 718.982.2984 \\ E-mail: knikou@mail.csi.cuny.edu, \\ m-knikou@northwestern.edu
}

Neuroscience Letters, Vol. 423, No. 1 (August 2015): pg. 18-23. DOI. This article is (C) Elsevier and permission has been granted for this version to appear in e-Publications@Marquette. Elsevier does not grant permission for this article to be further copied/distributed or hosted elsewhere without the express permission from Elsevier. 